\title{
The Applicability in Selection of American sitcoms as Materials for Teaching English listening and speaking
}

\author{
Sun Quan \\ School of Foreign language, \\ Yunnan Technology and Business University, P.R. China, \\ Linussun@126.com
}

\begin{abstract}
English Sitcoms are widely welcomed by teachers and students, but it has been debatable whether they are suitable for teaching material in English teaching. Though in these sitcoms spoken English with full-filled humor is the main feature, there is still a long distance between real and Actors' lines. Through English spoken feature, we take American popular long sitcom "Friends" and "Big Bang" as the example, combined the analysis of real spoken language in the sitcom in order to dig out the suitability when we need to select appropriate teaching material.
\end{abstract}

Key words- Applicability, American sitcom,

\section{Introduction}

Upon the time of extensive application of multimedia teaching methods in college English class, multimedia teaching material has become indispensable in college English teaching. The value of English video works as the teaching resource has been fully recognized, whose advantages lie in:

Visualization The integration of variety of information such as text (captions), sound, images and other media help students more easily understood;

Excitation The English video works create a lively learning background for students, greatly arousing the students' interest and enthusiasm, and encouraging them to energetically participate in learning activities;

Authenticity The English video works also create a locale being close to real life, from the standards of different races or countries, even classes and discrepancies on pronunciation and intonation, popular vocabulary of western society and cross-cultural background knowledge as well. Anyway students can natural acquisition through those real locales;

Accessibility With the opening of cultural product market, the English Filmography increasingly are getting more and more abundant, timely updates, so that teachers and students are now easier to find and access to those material for their language learning.

The comedy is the most favorite material. On the one hand, comedy contains visual, amusing and spiritual enjoyment, especially in long sitcom, which provides an ample scenes of life, a lot of authentic language, depicting the life of Western countries, so the teachers are willing and widely adopted them as teaching materials; on the other hand, more and more students are so interested in this relaxed, personal, learning through entertainment that they consciously enjoy and use the sitcom in and after class, in order to improve their own foreign language listening and speaking ability. There is no doubt, by watching sitcoms students achieve internalization of knowledge in monasteries, and to improve foreign language proficiency. However, English sitcoms are widely welcomed by teachers and students, but it has been debatable whether they are suitable for teaching material in English teaching. As we all know, the goal why the birth of the first sitcom is to serve and entertain the public, which makes humor mainly through the spoken language everywhere in the show. Though in these sitcoms spoken English with full-filled humor is the main feature, there is still a long distance between real and Actors' lines. Through 
English spoken feature, we take American popular long sitcom "Friends" and "Big Bang" as the example, combined the analysis of real spoken language in the sitcom in order to dig out the suitability when we need to select appropriate teaching material.

\section{Classification and characteristics of spoken language}

There are two forms of language that are spoken and written language, both of which are mutually independent and complementary. As per the length of time to organize speaking, oral language can be divided into impromptu spoken colloquial (Spontaneous Language), prepared oral (Planned Language) and scripting spoken (Scripted Language or Planned-to- the-last word Language).

Impromptu speaking, as the name implies, whose meaning is no time to prepare. The speaker does know nothing about the content of conversation or speech in advance but then play their own language on a particular or ad hoc subject to express their own thoughts and ideas. Oral improvisation is the type of people speech which is mainly used in daily communication.

Prepared oral, Some namely speakers has been advised of the subject or content of speech, and give some time to prepare, and even wrote an outline, and allow to bring pieces while having speech. Because the speaker lays a plan, or to bring an outline sheet as a reminder, therefore it is considered impromptu speaking; debate is a typical example.

Scripting spoken, which is ready sufficiently, and always around a purpose to carry out, and therefore the content is more refined compared with the previous one, and in strict accordance with the requirements of the speakers expressed a prepared manuscript, such as broadcast press releases.

The above three types of spoken language have significant differences in their style, tone, rhythm, speed, information, vocabulary, grammar and fluency.

The language we discusses in comedy sitcom belongs to script spoken, commonly known lines. Lines is a special kind of literary language, which has the following characteristics:

Action: it requires the actor not only express idea with body language, but also reveal character, personality, emotional task;

Characterization: it serves a specific character in accordance with their origin, age, occupation, education, experience, social status and the times they stayed;

Incisiveness: the lines must be simple but rich in content and rhetoric before and after care;

Hybridizing: Essence has written and spoken of convenience communication features, the actors with spoken language and body language of the written conversion; And for comedy, it's also ironic, variable, metaphorical and exaggerated, but compared with the real life, its language lack of authenticity.

\section{Searching and analyzing the suitability of selection of materials}

Whether the material is suitable for teaching depends on authenticity of contents. As to how to pursue "real", different scholars have issued their advocations. Nunan advocates the usage of getting directly from the real communication, rather than specially preparing materials for English teaching, after then Geddes and White complement such theory on the basis of Nunan, that is both completed and authentic materials are not only adopted, but also presented characteristics of high-frequency communication in real emerging materials. And Widdowson issued that real authenticity corpus should be distinguished from real corpus that is kind of unmodified corpus from real life, and whether corpus is "real" or not should depends on the reaction of learners to interact with the material; if learner made a proper response, then the material can be regarded as real. In the selection of the sitcom as the teaching material, teachers often see only the authenticity of the source, but ignored the inauthenticity ingredients spoken in sitcom. The discussion in terms of rate of speech, tone, grammar, and communicative principle sitcom is suitable for use. 


\subsection{Speed of Speech}

"Speed" refers to the flow rate of speech when you are speaking, which is the primary element that teacher need to consider when teachers choose teaching material in advance. Generally, people from countries speaking English whose rate of speech in daily communication is 150 to 170 words per minute; rate of news broadcast (according to $\mathrm{ABC}$ 's data) is more than 200 words per minute. After analyzing data of random check by a Speed Test Tool, the rate of actors of "Friends" reach to an average of 210 words per minute, and some actor even add up to 240 words per minute. Such test results are in line with the features of script, also common in similar comedies. Since those lines are prior well-organized, and after several rehearsals, actors are very familiar with their lines already, and therefore impromptu oral are more faster and smoother, even if there is hesitation or pause, deliberate acting make the show more natural, and more realistic, so it is commonly that the Speed of sitcom is faster than the daily exchange by $30 \%$. According to China's syllabus of CET-4, students are required to understand the listening passage of 140 words per minute;CET-6 required to 170 words / minute; TEM- 8 required 200 words / minute. Therefore, if you choose sitcom as teaching material for the hearing, the ability of full-understanding for students will primarily be considered about, even reasonable teaching goals. Speed is one of the variables that affect students' listening comprehension, together with other factors, such as vocabulary, background knowledge, which are likely to make the material more difficult to understand, so selecting sitcom like "Friends" as teaching materials for college students may constitute considerable difficulty.

\subsection{Intonation}

As to learn spoken English well, to imitate intonation is very important element for beginners learning English. Filmography provides variable accent and way of speaking from different place. However, when the same actor imitate tone from different persons, the teachers and students must have a clear understanding for the work, as it has specialty that is the stylistic lines with actors' feeling show style duality.

\subsection{Grammatical structure}

Compared with the movie, one of the prominent features of the sitcom relies on many dialogues coming from habits, jokes, even idioms, which reflect daily life. Therefore script lines of sitcom have more simple, complete sentences and loose sentences, and more redundant words. The sitcom shows advantages that are simple grammatical structures, spoken distinctive characteristics, which will help students make oral output. In contrast, the movies adapte long sentences, independent nominative and other abstruse grammatical structure, the use of "big words" which make viewers feel it difficult to understand. Therefore, sitcoms are more easily understood by students than other similar visual material from the grammatical structure analysis.

\subsection{Communicational principle}

The ultimate goal of language learning is to master right way to communicate. Therefore, the choice of teaching materials carefully considers the authenticity in communication, as far as possible so that students learn to use the language in real communication background. But in view of the Sitcom, if we want to find such suitable for teaching use of communicative situation is disappointed us, on the contrary, violation of the principles of communication and language fall scenes abound.

As a comedy, many classic jokes, making impromptu comic gestures and remarks, mocking between mates, exaggerated humor definitely make sitcom very successful, but those spoken language also has "a serious violation of the principles of communication" features. In daily communication, such way of joking will be nothing but being considered impolite, and even lead to offend and hurt bitterly. If you allow students to use those language without distinction, they will not only affect the students' pragmatic competence, but also set a huge obstacle for their real language communication activities. 


\section{Conclusion}

When we plan to use visual material as aid in classroom, not only In order to allow students to master the correct pronunciation, grammar and expand your vocabulary, but also let them deeply acknowledge the cultural background, social customs, and the principles of communication. Though the sitcom as teaching materials has its own advantage, such as lively content, newest language, humorous corpus, rich scenes of life, and also compensate for the insufficiency of textbooks, teachers should be considered about the selection of new words, cultural background, scene settings and other factors. We must also take into account factors like speech rate, intonation, grammatical structure, communication principles. Although there is no syntax long sentences frequently, complex sentences and other written characteristics, relatively fast Speed in news broadcasting, the actor's artificial exaggerating intonation, the violation of the principles in communicative scene are not our option in listening and speaking course. When we decide to adopt sitcom as teaching materials, teacher should play a good role of coordinator, being fully aware of the difficulty of this material, and giving students timely guidance, pointing out the problem when students are doing oral and listening practice to help them fulfill purposes of master proper application of language in the sitcom.

\section{Reference}

[1] McCarthy, M. Discourse Analysis for Language Teachers. Cambridge University Press, 1991: 90- 94.

[2] Hedge, T. Teaching and Learning in the Language Classrooms [M] .Oxford: Oxford University Press, 2000: 245

[3] Nunan, D. Second Language Teaching and Learning [M]. Heinle\&Heinle/Thomson Learning Asia, 2003:79.

[4] Geddes, M. and R. White. "The Use of Semi-scripted simulated authentic speech and listening comprehension" [J]. Audio- visual Language Journal 1978: 3: 137- 145.

[5] Widdowson, H. Teaching Language as Commnunication[ $\mathrm{M}]$.Oxford: Oxford University Press. 